\title{
Characterization of surface textures generated on hardened steel parts in high-precision machining operations
}

\author{
W. Grzesik • J. Rech $・$ K. Żak
}

Received: 22 September 2014 / Accepted: 11 January 2015 /Published online: 23 January 2015

(C) The Author(s) 2015. This article is published with open access at Springerlink.com

\begin{abstract}
This paper presents the comparison of surface textures produced by high-precision cutting and abrasive processes on hardened steel parts. Investigations include surfaces generated by hard turning, belt grinding, and superfinishing (external honing) operations. As a result, several surfaces generated with different process kinematics and the $S a$ roughness parameter of about $0.05 \mu \mathrm{m}$ were compared. Apart from the standard $2 \mathrm{D}$ and $3 \mathrm{D}$ roughness parameters, the fractal, motif, and frequency parameters were considered.
\end{abstract}

Keywords Surface texture $\cdot$ Hard machining $\cdot$ Belt grinding . Superfinishing

\section{Introduction}

Nowadays, the technological shifts in surface metrology allow the surface features generated by modern manufacturing processes (including hard part machining) to be characterized with a higher accuracy using a number of the field parameters

\author{
W. Grzesik $(\bowtie) \cdot$ K. Żak \\ Opole University of Technology, Str. Mikołajczyka 5, 45-271 Opole, \\ Poland \\ e-mail: w.grzesik@po.opole.pl \\ K. Żak \\ e-mail:k.zak@po.opole.pl \\ J. Rech \\ Laboratory of Tribology and Systems Dynamics, ENISE \\ Saint-Etienne, Saint-Etienne, France \\ e-mail: joel.rech@enise.fr
}

( $S$-parameters and $V$-parameters sets) [1]. Special attention in this area has been given during two past decades to the standardization of 3D set roughness parameters [1-3]. Precision machining with $R z=2.5-4 \mu \mathrm{m}$ and high-precision machining with $R z<1 \mu \mathrm{m}$ of hardened steels (45-60 HRC) with ultrahard cutting tool materials have been developed with a special interest to automotive, hydraulic, and die and mold industry sectors $[4,5]$ due to high flexibility, possible complete machining, lesser ecological impact, and higher MRR $[6,7]$. The discussion platform over the possible replacement of grinding by hard cutting was initiated in [8]. In particular, the capability profiles of cutting and grinding operations against the functionality of the machined surfaces were discussed. This is because hard turning and grinding, as well as other abrasive finishing operations, generate different surface structures which influence distinctly their functional properties. Unfortunately, this attempt includes only 2D height and amplitude parameters and the relevant bearing area curves (BACs) shapes [8]. However, these analyses showed a dissimilarity between the hard turned and ground surface topographies, although the $R a$ or $R z$ parameters are nearly the same. The $2 \mathrm{D}$ and $3 \mathrm{D}$ comparison, more oriented on bearing area parameters, related to precision hard turning and belt grinding is provided by Grzesik et al. [9]. Moreover, it was extended to superfinishing and ball burnishing operations [10] in order to check how nonremoval burnishing process can modify the characteristics of the turned surface. In this aspect, a special focus should be placed on surface finish and surface texture induced by these challenging operations $[9,10]$. The objective of this study is to comprehensively characterize and compare surface textures of representative hard turned and two abrasively treated surfaces using a number of standardized 3D roughness parameters as well as other characteristics such as fractal dimension, motif, and frequency parameters. The quantitative criterion was that the $S a$ and $S z$ roughness parameters are about 0.05 and $1 \mu \mathrm{m}$, respectively. 
Fig. 1 Conventional lathe with belt grinding head (a) and a scheme of belt grinding process with MQL supplying (b) a)

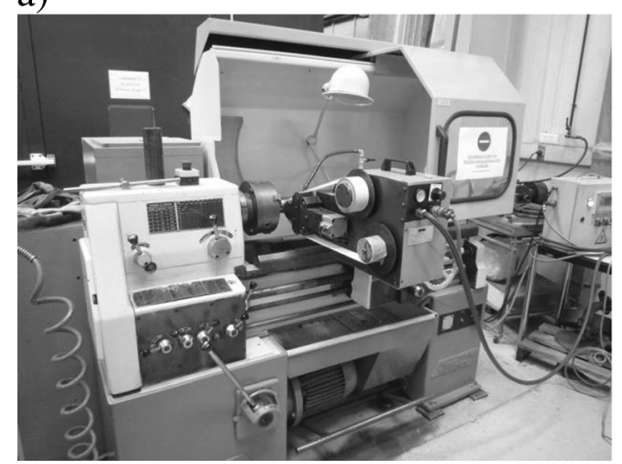

b)

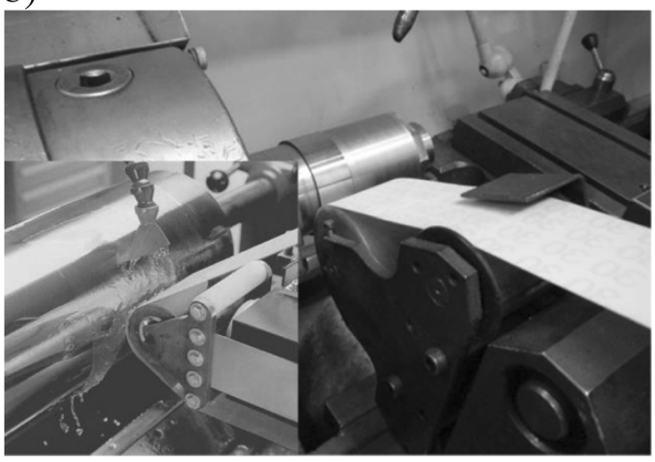

a) $S a=0.07 \mu \mathrm{m}, S z=0.78 \mu \mathrm{m}$

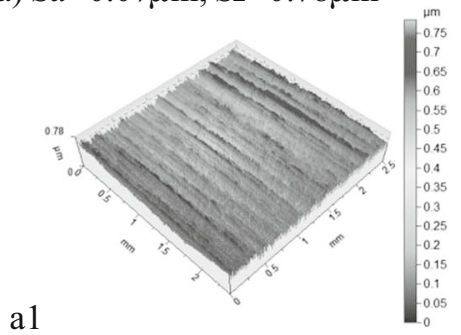

a1

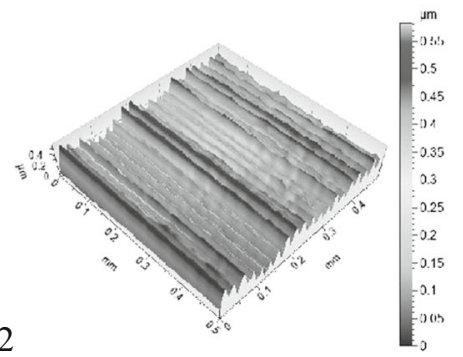

b) $S a=0.045 \mu \mathrm{m}, S z=1.33 \mu \mathrm{m}$

b1

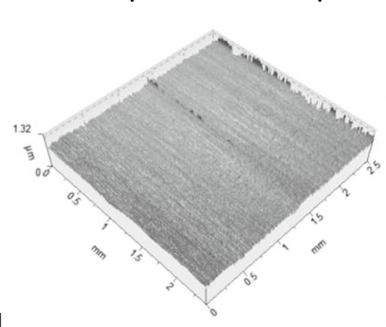

b2

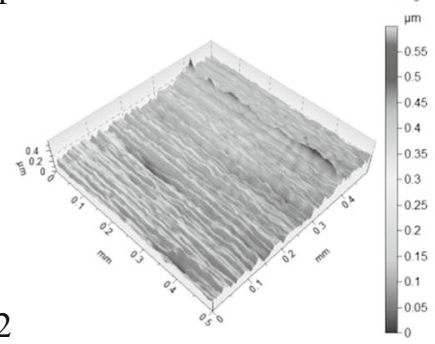

c) $S a=0.06 \mu \mathrm{m}, S z=1.20 \mu \mathrm{m}$

c1

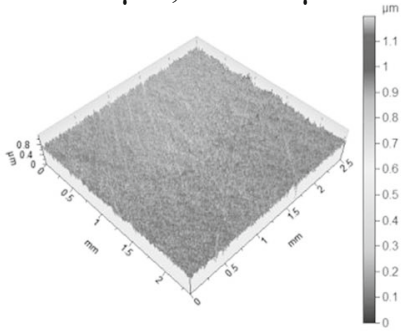

c2

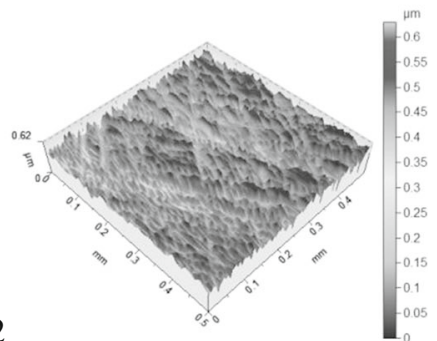

Fig. 2 Surface textures produced by HT (a), belt grinding (b), and superfinish (c); $a 1, b 1$, and $c 1$-isometric views with the scanned area of $2.5 \mathrm{~mm} \times$ $2.5 \mathrm{~mm} ; a 2, b 2$, and $c 2$ - isometric views with the scanned area of $0.5 \mathrm{~mm} \times 0.5 \mathrm{~mm}$

Fig. 3 Average values of $S a$ and $\mathrm{Sz}$ parameters obtained by HT, $\mathrm{BG}$, and SF operations

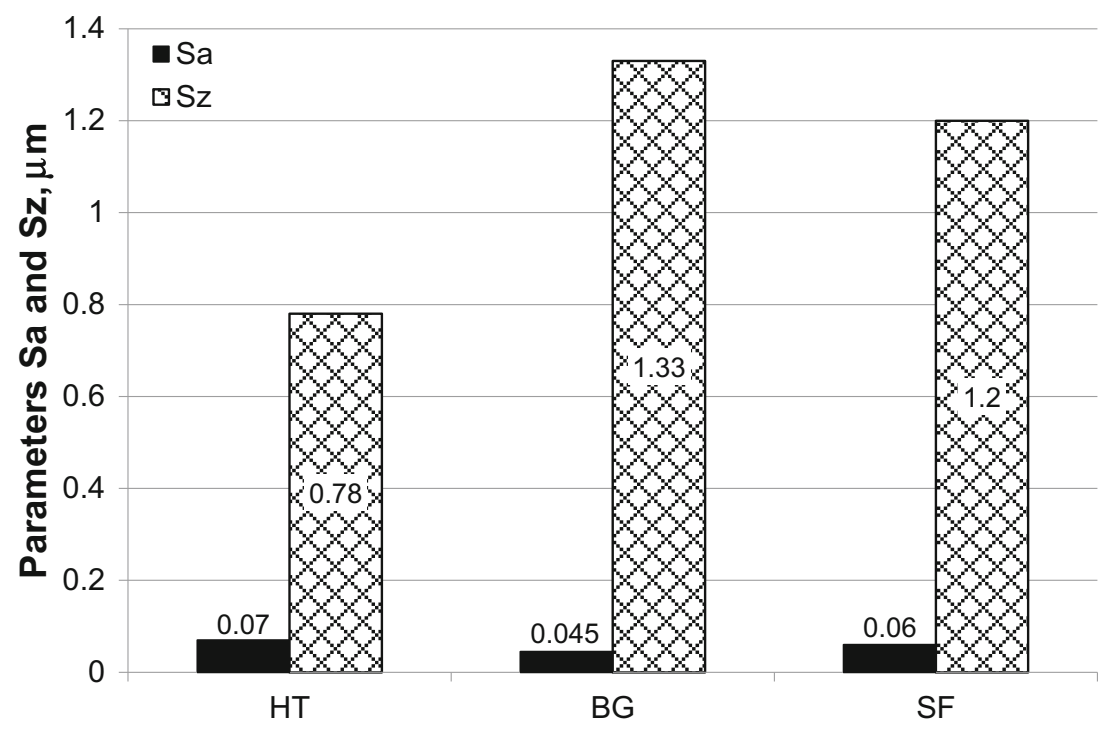


a) $\mathrm{Sal}=0.01$, isotropy: $0.68 \%$

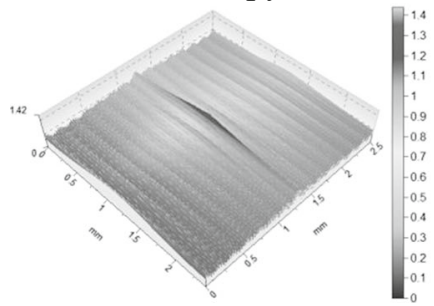

b) $\mathrm{Sal}=0.06$ isotropy: $5.19 \%$

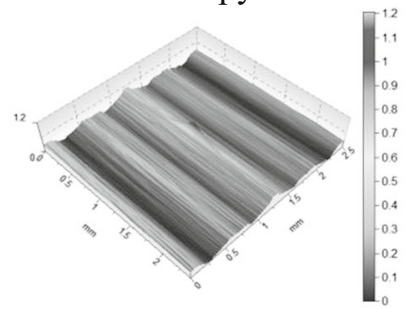

c) $\mathrm{Sal}=0.01$, isotropy: $12.8 \%$

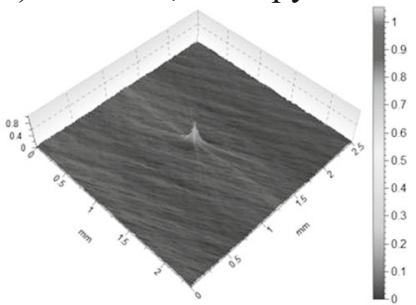

Fig. 4 Representative autocorrelation functions for turned (a), belt ground (b), and superfinished (c) surfaces

\section{Machining tests and surface measurements}

Hardened rings made of a $41 \mathrm{Cr} 4(57 \pm 1 \mathrm{HRC})$ with initial $0.4 \mu \mathrm{m} S a$ obtained by Cubic boron nitride (CBN) turning were optionally turned, belt ground, and superfinished in order to generate surfaces with the $S a$ roughness of about $0.05 \mu \mathrm{m}$. The machine tools were Okuma Genos L200E-M $\mathrm{CNC}$ precision turning center, special belt grinding device described in [9] and superfinishing head mounted in a conventional lathe described in [10].

Machining conditions for cutting and abrasive operations performed were as follows:

1. High-precision hard turning (HT) using TNGA 160408 S01030 chamfered CBN insert, cutting speed $v_{c}=150 \mathrm{~m} /$ $\mathrm{min}$, feed rate $f=0.025 \mathrm{~mm} / \mathrm{rev}$, and depth of cut $a_{p}=$ $0.03 \mathrm{~mm}$. Previously, surfaces were turned using the same cutting tool with feed rate of $0.05 \mathrm{~mm} / \mathrm{rev}$ and depth of cut of $0.05 \mathrm{~mm}$.

2. Two step oscillation belt grinding (BG) using abrasive belts with 30 and $9 \mu \mathrm{m}$ grains. Rotation speed of the workpiece was $900 \mathrm{rev} / \mathrm{min}$, belt feed was $0.06 \mathrm{~mm} / \mathrm{rev}$, oscillation frequency was $12 \mathrm{~Hz}$, oscillation amplitude was $\pm 0.5 \mathrm{~mm}$, and roller pressure was 2 bars. Belt grinding (Fig. 1) was performed during $9 \mathrm{~s}$ with supplying oil mist produced by a MQL system.

3. Superfinish (SF) using 99A320N10V ceramic stone, oscillation frequency of $680 \mathrm{osc} / \mathrm{min}$ and amplitude of $3.5 \mathrm{~mm}$, applied force of $40 \mathrm{~N}$, and cooling and lubrication medium $85 \%$ kerosene and $15 \%$ machine oil.

Surface topographies generated by HT, BG, and SF operations were recorded using a $3 \mathrm{D}$ contact profilometer with a diamond stylus radius of $2 \pm 0.5 \mu \mathrm{m}$ and an Alicona noncontact device. The determination of $3 \mathrm{D}$ roughness parameters and $3 \mathrm{D}$ visualization of machined surfaces were performed using a Digital Surf, Mountains ${ }^{\circledR}$ Map package. The characterization of surface topographies was based on four groups of parameters including (a) standardized 3D surface roughness parameters: height, amplitude, horizontal, hybrid, and functional [11]; (b) fractal dimension; (c) standardized motif parameters; and (d) characteristics of frequency spectra recorded.

\section{Experimental results and discussion}

\subsection{Characterization of surface topography}

Representative surface topographies obtained in hard turning (HT) and abrasive (BG, SF) operations performed are visualized in Fig. 2a-c using a special zooming technique. In terms of the surface quality criterion, both operations can be classified as high-precision machining $-R z \approx 2 \mu \mathrm{m}$ [8]. As shown in Fig. 2, the measured values of $S a$ oscillate between 0.045 and $0.07 \mu \mathrm{m}$. As depicted in Fig. 3, Sz parameter ranges from 0.78 for hard turning to 1.20 and $1.33 \mu \mathrm{m}$ for SF and BG operations, respectively. It means the comparison of the turned and

a) $1-S d c=0.199 \mu \mathrm{m}, S x p=0.16 \mu \mathrm{m}, 2-S d c=0.115 \mu \mathrm{m}$, $S x p=0.12 \mu \mathrm{m}, 3-S d c=0.138 \mu \mathrm{m}, \operatorname{Sxp}=0.18 \mu \mathrm{m}$

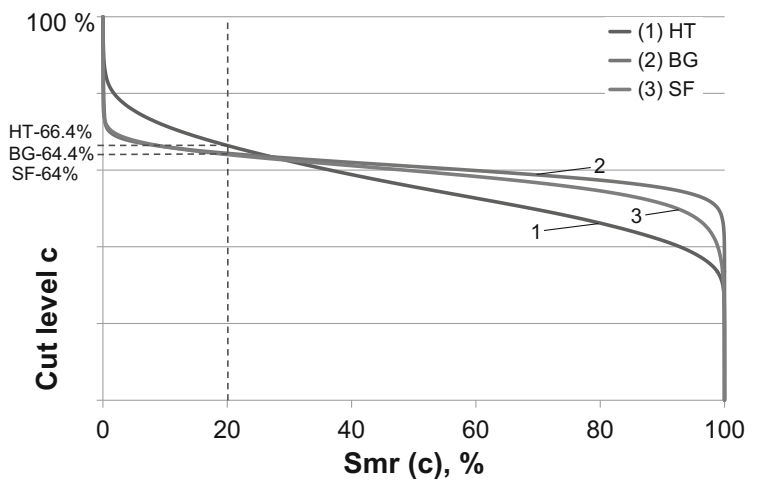

b) 1 - $S s k=0.17, S k u=2.60 ; 2-S s k=-0.07, S k u=5.31$, $3-S s k=-1.03, S k u=6.13$

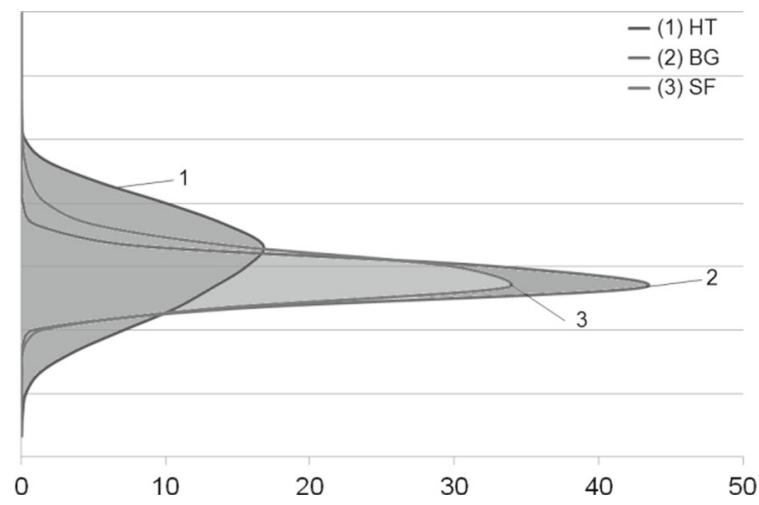

Fig. 5 3D BAC shapes (a) and ADF distributions (b) for hard turned (1), belt ground (2), and superfinished (3) surfaces 


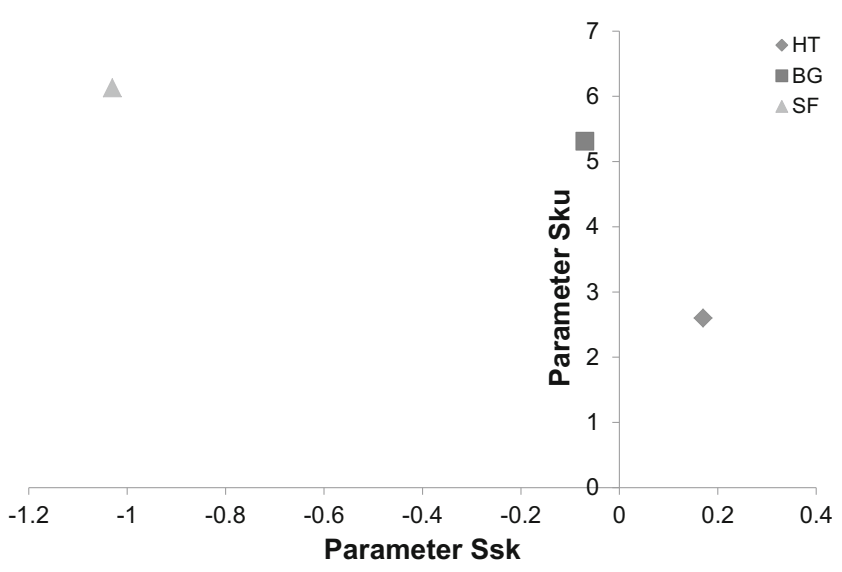

Fig. 6 The envelope showing shifts of Ssk and Sku parameters resulting from abrasive operations

abrasively treated surface textures keeping height $R z(S z)$ parameter constant seems to be questionable.

The strong anisotropy of all machined surfaces shown in Fig. 2 is confirmed by characteristic shapes of the autocorrelation function (AACF) presented in Fig. 4. The turned surface is periodic-anisotropic (Fig. 4a) but the abrasively treated surface is mixed, between anisotropic and random structures (Fig. 4b, c). The values of the fastest decay autocorrelation length $(\mathrm{Sal})$ are equal to 0.01 for hard turned and 0.06 or 0.01 for abrasive treated surfaces, respectively. A larger $S a l=0.06$ for the belt ground surface (Fig. 4b) suggests that its texture is compounded of low spatial frequency components due to copying of ultra-fine grains embedded into abrasive belts (see Fig. 13a).

\subsection{Characterization of function-related parameters}

Figure 5 presents the shapes of 3D BACs and associated Amplitude density function (ADF) curves obtained for the compared machining operations. In particular, as shown in Fig. 6, hard turning produces surfaces with a positive skew Ssk $=0.17$ (HT) while finish belt grinding generates surfaces with a small negative skew $S s k=-0.07$ (BG), which visibly increases when superfinish is performed ( $S s k=-1.03$ for $\mathrm{SF}$ ).
Moreover, Fig. 5b suggests that hard turning and abrasive operations produced topographies with distinctly different ADF shapes, which result in various bearing and contact properties. The superior bearing properties corresponding to $S s k=$ -1.03 were obtained when sharp irregularities produced by hard turning were removed by abrasive stone during superfinishing (BAC \#3 in Fig. 5a). It can be noted in Fig. $5 b$ that the ADF curve is similar to a typical bell (Gaussian) curve because the kurtosis value is close to 3 $(S k u=2.60)$. On the other hand, the ADF curves are distinctly sharper when the initial turned surface is modified by belt grinding or even more by superfinish (kurtosis increases to 5.31 and 6.13 , respectively).

Additionally, values of the areal material ratio $\operatorname{Smr}(c)$, the inverse areal material ratio $S d c(m r)$ and the peak extreme height $S x p$ are given in Fig. 5a. In Fig. 9a, they are analyzed in terms of areal $(V)$ parameters including the reduced core $(S k)$, peak $(S p k)$, and valley $(S v k)$ height or their specific ratios (Spk/Sk, Svk/Sk, Spk/Svk).

Additional information on the fluid retention can be obtained using an original technique of the vectorisation of microvalleys network (Fig. 7) generated on the machined surface [2, 3]. The maximum depth of valleys is between 0.35 and $0.55 \mu \mathrm{m}$ and their widths 0.08 and $0.16 \mu \mathrm{m}$ depending on the sequence of machining operations performed. Additionally, the average density of valleys is between 650 and $950 \mathrm{~cm} / \mathrm{cm}^{2}$, respectively (the lower value corresponds to the turned surface and the higher one to the superfinished surface). This comparison indicates that abrasive operations produce surfaces with a larger number of more densely distributed valleys (Fig. 7b, c). As a result, the functional properties of these two groups of surfaces should be different. These data coincide well with the distributions of the volume functional parameter ( $V m p$ and $V v v)$ shown in Fig. 8.

The functional analysis of the 3D BACs is based on the four volume parameters including the peak material volume $(V m p)$, the core material volume $(V m c)$, the core void volume $(V v c)$, and the valley void volume $(V v v)$ parameters $[1,2,12]$.

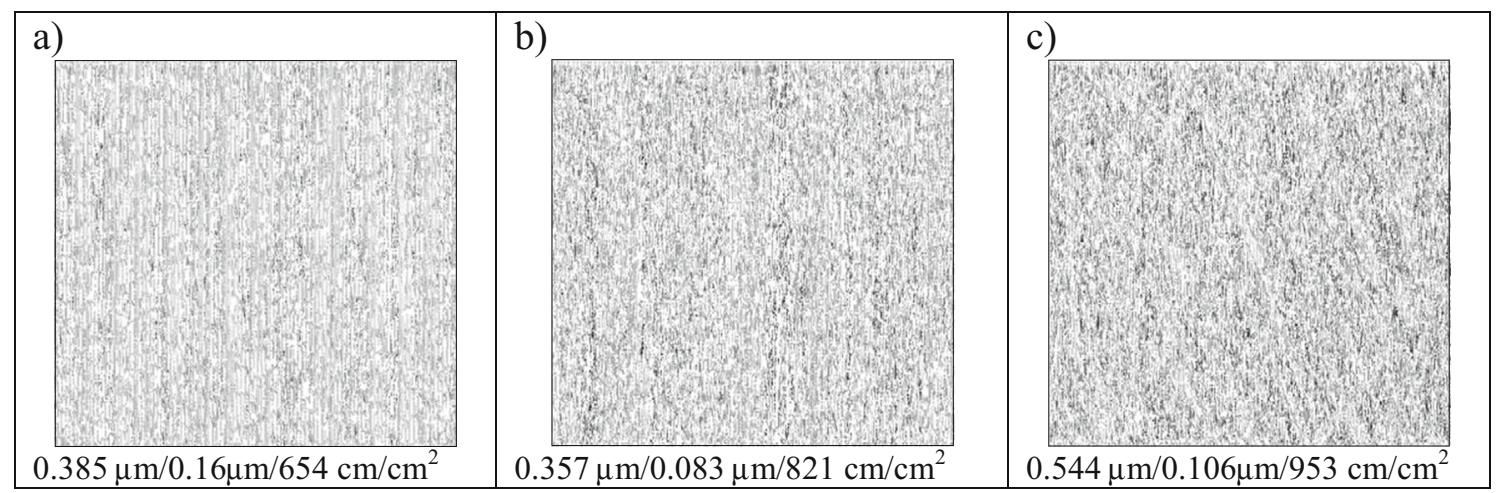

Fig. 7 Vectorized micro-valley networks for turned (a) and ground (b) and superfinished (c) surfaces. Three values give the average depth, width, and density of micro-valleys 
a)

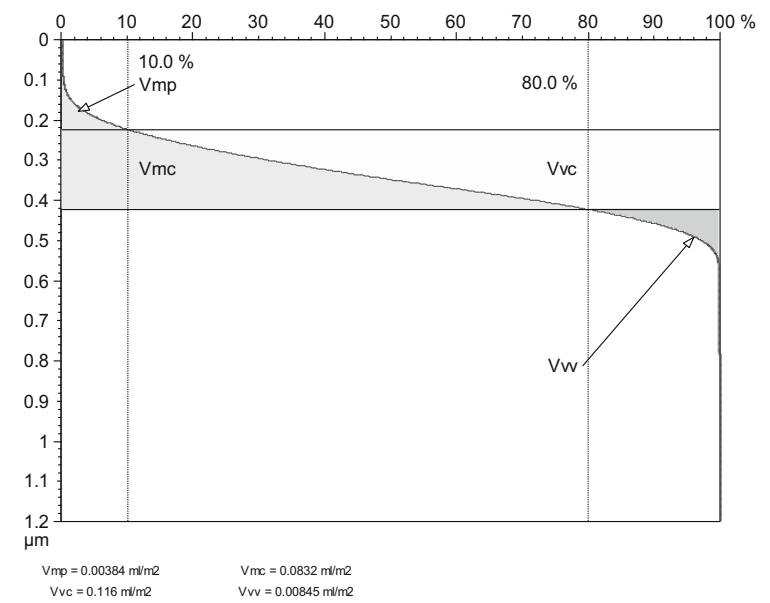

b)

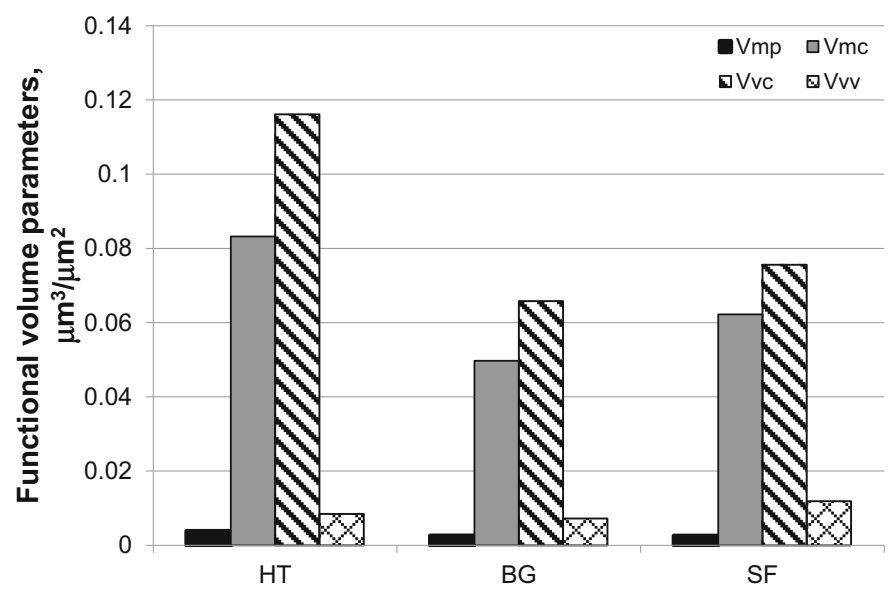

Fig. 8 Distribution of surface volume parameters for surfaces generated by HT (a) and their comparison for HT, BG, and SF operations (b)

Their values obtained for HT and abrasive operations are as follows (in order $\mathrm{HT} / \mathrm{BG} / \mathrm{SF}$ ): $V m p=0.0038 / 0.026 /$ $0.0026 \mu^{3} / \mu^{2} ; V m c=0.083 / 0.050 / 0.062 \mu \mathrm{m}^{3} / \mu \mathrm{m}^{2} ; V v c=$ $0.116 / 0.066 / 0.076 \mathrm{\mu m}^{3} / \mu^{2}$; and $V v v=0.0084 / 0.0072 /$ $0.0119 \mu^{3} / \mu^{2}$. For instance, higher values of $V v v=$ $0.0119 \mu^{3} / \mu \mathrm{m}^{2}$ confirm better fluid retention ability of superfinished surfaces (for turned surface $V v v=0.0084 \mu^{3} /$ $\mu \mathrm{m}^{2}$ is about $30 \%$ lower). This fact coincides with the relevant densities of micro-valleys in Fig. 7.

The comparison between the function related parameters [12] are given in Fig. 9. In these case studies, three ratios of various areal material ratio parameters- $S p k / S k, S v k / S k$, and $S p k / S v k$ - were used in order to asses the nature of the particular surface textures. The ratio of $S p k / S k$ may be helpful to distinguish between two surfaces with indistinguishable roughness average $S a$ [13]. In fact, surfaces generated by cutting and abrasive tools with the same $S a$ have slightly different $S p k / S k$ values of 0.333 (HT), 0.308 (BG), and $0.267(\mathrm{SF})$ as shown in Fig. 9a. On the other hand, $S v k / S k$ ratio is equal to 0.208 for turned surfaces and increases vastly to 0.54 and 0.60 for surfaces produced by BG and SF operations. Also Spk/Svk ratio is distinctly different -1.6 for HT and about 0.5 for abrasive operations. As shown in Fig. 9b, the ratio of $S p k / S k$ correlates well also with the $V m p$ parameter, whereas the ratio of $S v k / S k$ with $V v c$ volume parameter and micro-valleys density. Additional relationships can be observed (Fig. 9a) between the ratio of $S p k / S v k$ and $S d c$ and $S x p$ material ratio parameters.

\subsection{Characterization of spatial and hybrid parameters}

The set of 3D parameters includes four spatial parameters, three of which are texture parameters. The belt ground and especially superfinished surfaces contain distinctly more summits within the scanned area $-S d s=3421.21 / \mathrm{mm}^{2}$ (SF) versus $1788.61 / \mathrm{mm}^{2}(\mathrm{HT})$. The small texture aspect ratio $S t r=$ 0.01-0.05 for turned and ground surfaces indicates stronger directionality (anisotropy); its values less than 0.1 are characteristic for highly anisotropic surfaces [11] (for SF is something higher of 0.13 ). The texture direction $S t d$ close to $90^{\circ}$ for HT and BG surfaces indicates that the dominant surface lay is perpendicular to the measurement direction (for SF operation $S t d=112.5^{\circ}$ which results from crossing lays shown in Fig. 2c). The values of Sal parameter are given in Fig. 4.

a)

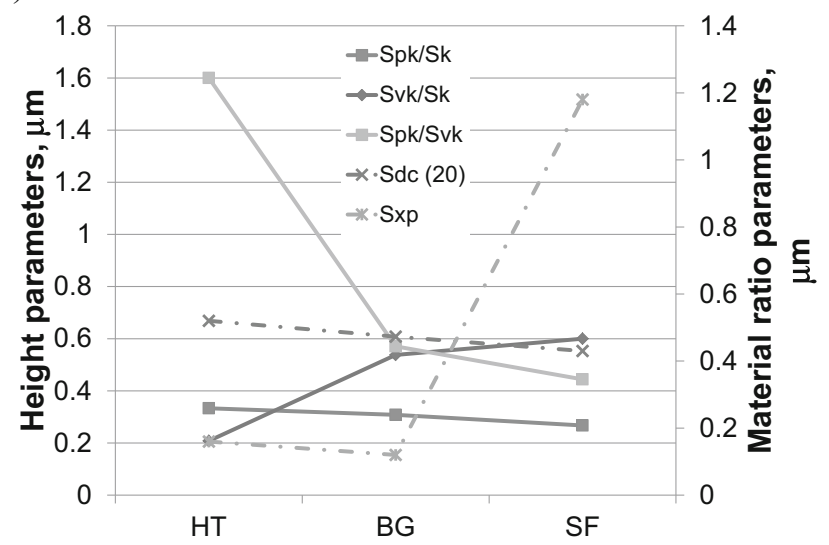

b)

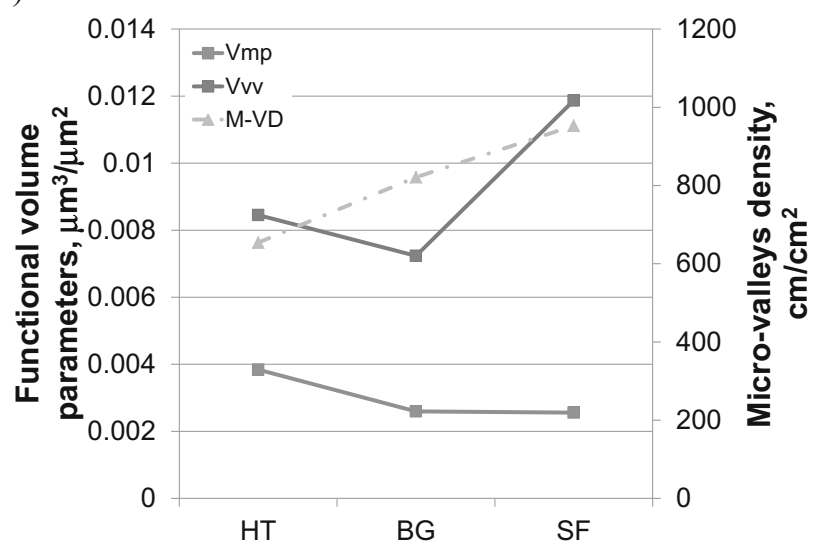

Fig. 9 Functional relationships between selected 3D V-parameters 
Fig. 10 Example of the motif graph for hard turned (a), belt ground (b), and superfinished (c) surfaces a)

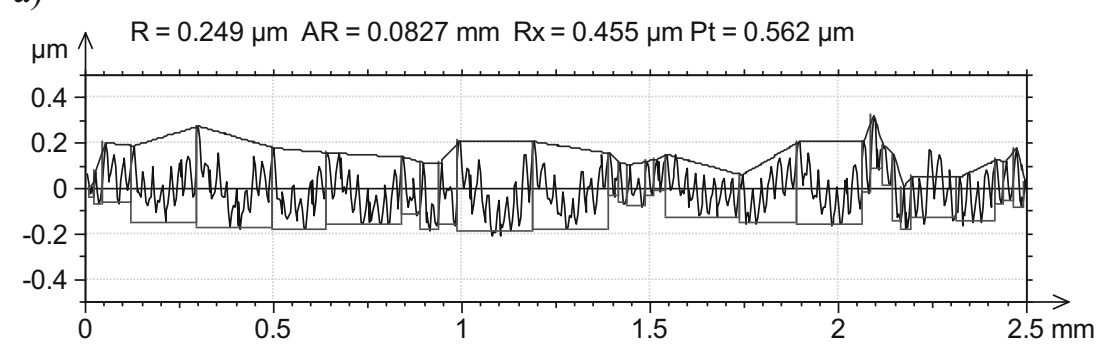

b)

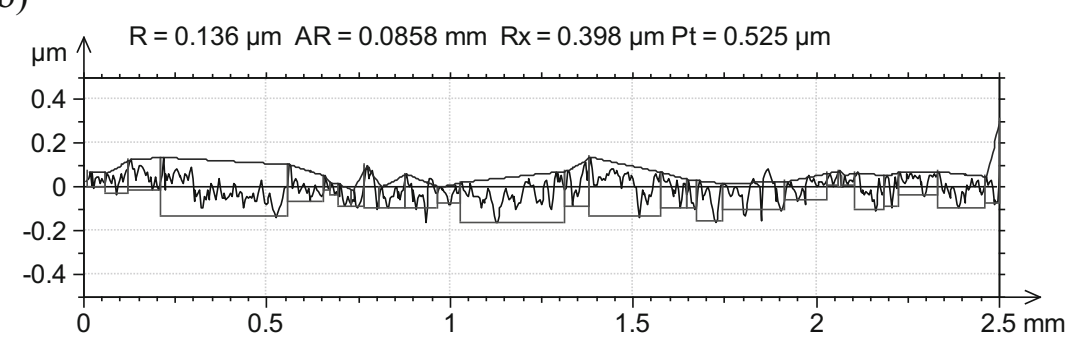

c)

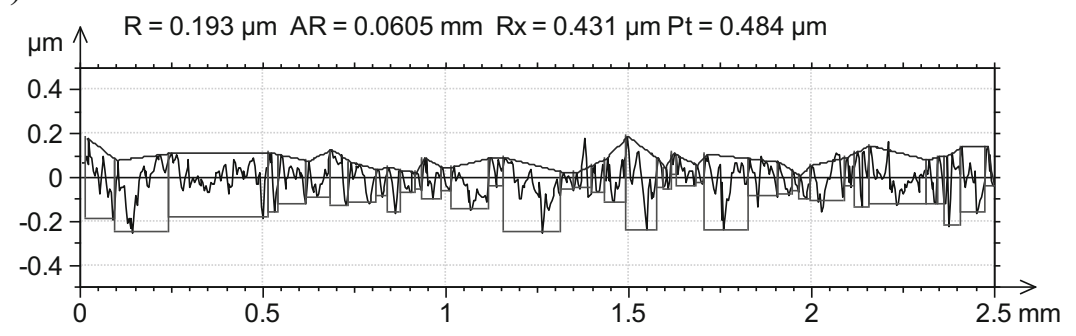

Values of three 3D hybrid parameters emphasize additional geometrical differences in the compared textures. Very low slopes $S d q$ of $0.01-0.02$ were obtained for all machined surfaces which suggest their high optical quality. The values of the average summit curvature $S s c$ are between 0.005 and $0.007 \mu^{-1}$ which are typical for machined surfaces $(0.004$ $0.03{\mu \mathrm{m}^{-1}}$ given in [11]). The $S d r$ parameter (the developed interfacial area ratio) of $0.01-0.02 \%$ is obtained.

\subsection{Motifs and fractals}

The motif analysis is performed on the unfiltered surface profile divided into a series of windows [11], as exemplarily shown in Fig. 10. The three parameters - the mean depth of roughness motif $R$, the mean spacing of roughness motif $A R$, and the largest motif height $R x$ were analyzed.

The values of $R x$ are comparable, although turned surfaces include slightly deeper pits $(R x=0.45 \mu \mathrm{m})$ than belt ground and superfinished surfaces $(R x=0.4 / 0.43 \mu \mathrm{m})$ which is in accordance with volume bearing parameters (Fig. 8). Figure 11 shows that the $R x$ motif parameter is stronger correlated with the $S z$ parameter rather than $R z$, although motifs are based on $2 \mathrm{D}$ analysis. On the other hand, the $R$ motif parameter of 0.14 $0.25 \mu \mathrm{m}$ better coincides with the $R z$ changes.
The values of fractal dimension $S f d$ determined by means of the method of enclosing boxes are equal to $2.53,2.54$, and 2.71 for turned, belt ground, and superfinished surfaces, respectively.

Functional relationships between fractal dimension $S f d$ and $S a l, S s c$ and $S d s$, spatial and hybrid parameters were revealed. In Fig. 12, the $S f d$ is strongly correlated with the density of summits $(S d s)$, and $S f d=2.71$ corresponds with the maximum value of $S d s=3421.2 \quad 1 / \mathrm{mm}^{2}$ determined for superfinished

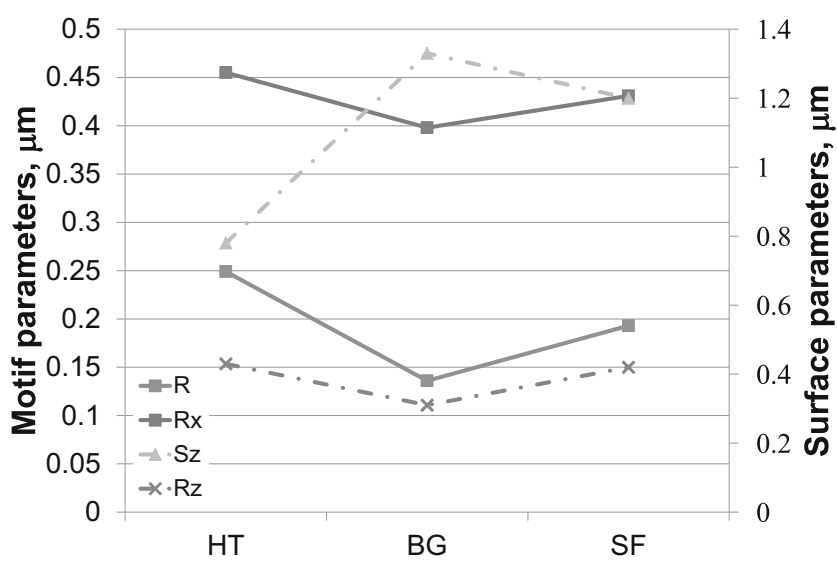

Fig. 11 Functional relationships between $S z(R z)$ and $R x(R)$ motif parameters 
a) Sfd: HT-2.53, BG-2.54, SF-2.71 Sds: HT-1788.63 1/. $\mathrm{mm}^{2}$, BG-3001.63 1/ $\mathrm{mm}^{2}$, SF-3421.20 1/. $\mathrm{mm}^{2}$

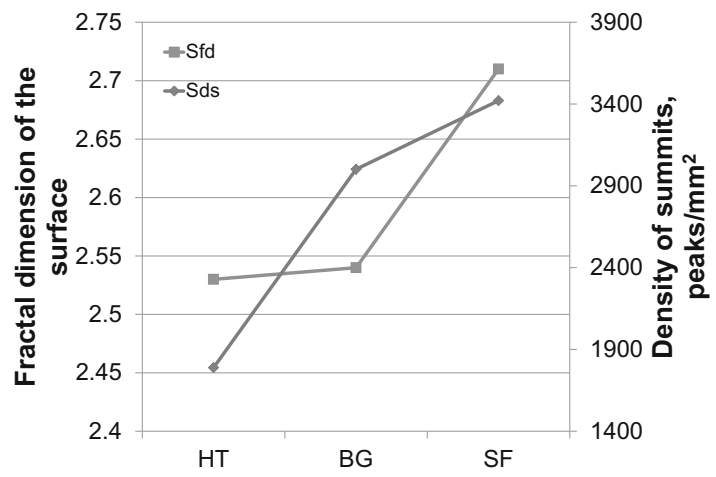

b)

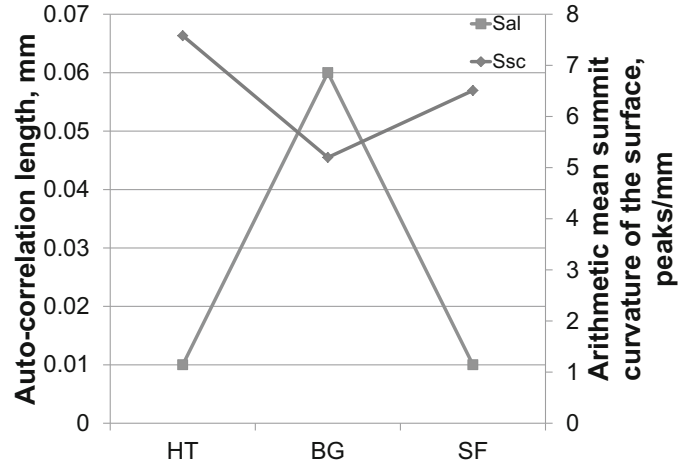

Fig. 12 Functional relationships between selected 3D S-parameters and fractal dimension

Fig. 13 Averaged power spectral density for turned (a), belt ground (b), and superfinished (c) surfaces a) Amplitude: A-0.0355 $\mu \mathrm{m}, \mathrm{B}-0.0208 \mu \mathrm{m}$

Wavelength: A-0.178 mm, B- $0.303 \mathrm{~mm}$

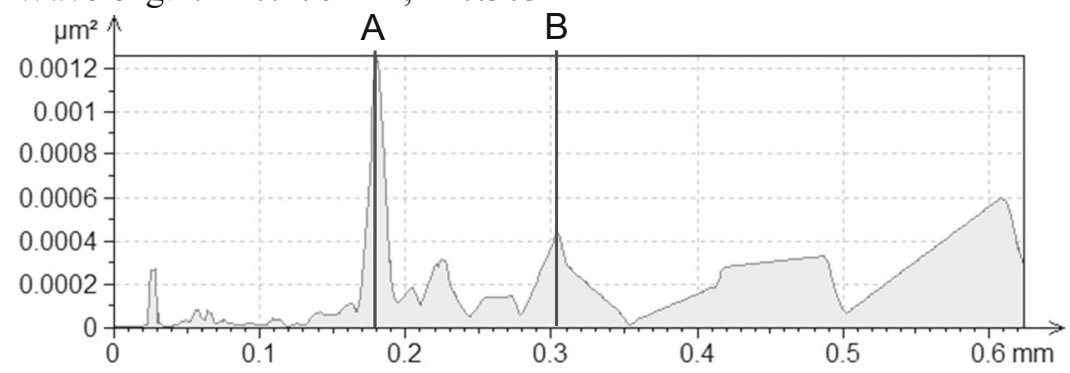

b) Amplitude: A-0.0161 $\mu \mathrm{m}, \mathrm{B}-0.0157 \mu \mathrm{m}, \mathrm{C}-0.0276 \mu \mathrm{m}$;

Wavelength: A- $0.403 \mathrm{~mm}, \mathrm{~B}-0.419 \mathrm{~mm}, \mathrm{C}-0.605 \mathrm{~mm}$

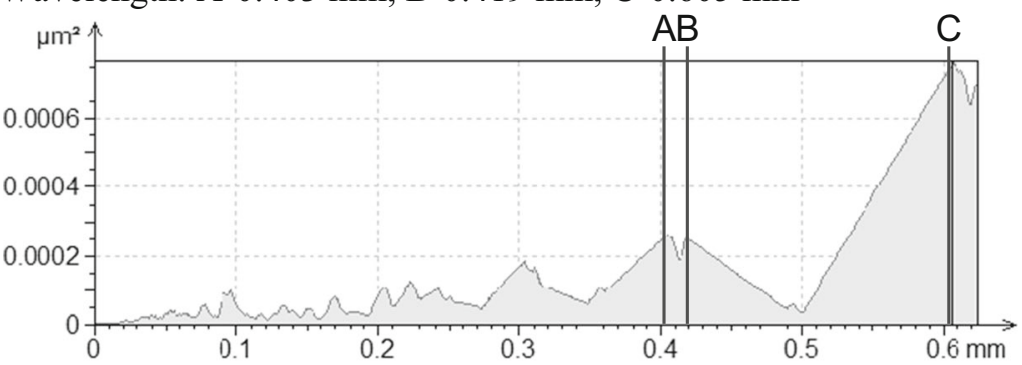

c) Amplitude: A-0.0191 $\mu \mathrm{m}, \mathrm{B}-0.019 \mu \mathrm{m}, \mathrm{C}-0.0179 \mu \mathrm{m}$;

Wavelength: A- $0.157 \mathrm{~mm}, \mathrm{~B}-0.247 \mathrm{~mm}, \mathrm{C}-0.349 \mathrm{~mm}$

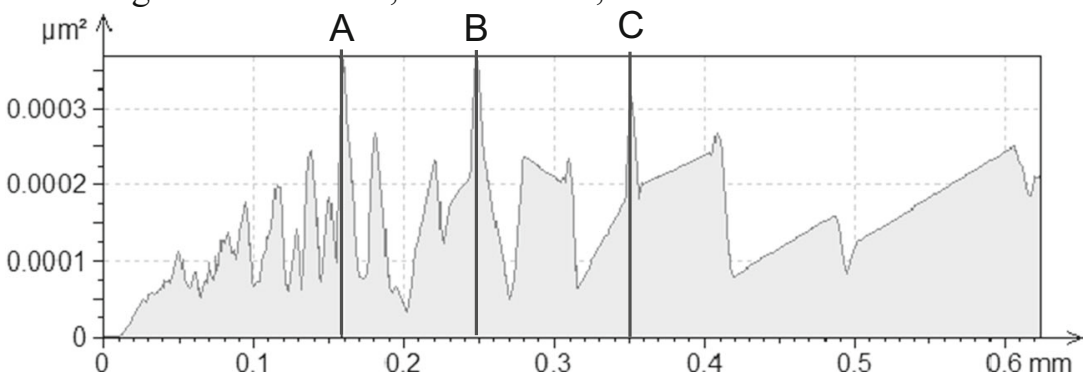


surface. At the second order, it deals with the arithmetic summit curvature $(S s c)$ and the autocorrelation length Sal parameter which characterize the uniformity of the texture.

\subsection{Frequency analysis}

The characteristic power spectral density (PSD) obtained for hard turned and ground surfaces are presented in Fig. 13. The PDS is very sensitive for all disturbances of the generated surfaces appearing in the machining system.

It is evident in Fig. 13a that the PSD spectrum contains only one dominant low-frequency component with the wave length something lower than the feed rate of $0.025 \mathrm{~mm}$ $(25 \mu \mathrm{m})$ and the amplitude of $0.035 \mu \mathrm{m}$. On the other hand (Fig. 13b), the belt ground surface contains two components with longer wavelengths but distinctly lower amplitudes, below $0.02 \mu \mathrm{m}$, than for hard turning. Comparable small amplitudes of about $0.02 \mu \mathrm{m}$ were recorded for surfaces produced by superfinish, although belt grinding is more stable (dynamic effect after abrasive processes depends on the structures of initial textures).

\section{Conclusions}

This study clearly indicates how high-precision machining operations can be performed in order to obtain desired surface texture and functional properties, i.e., resistant to wear, fluid retention ability, resistant to contact loads.

Although attributes of turned and ground and honed surfaces are described by the same $S a$ parameter of about $0.05 \mu \mathrm{m}$, their spatial features and functional properties are distinctly different.

The distributions of the PSD (APSD) function and vectorial maps of micro-valleys suggests that the textures of hard turned and ground and honed surfaces are periodic-anisotropic and mixed periodic-random anisotropic, respectively.

3D BAC curves and appropriate functional parameters indicate that honed hard surfaces have enhanced fluid retention abilities. This is due to negative $S s k$ value and up to three times higher $V v v$ volume in comparison to hard turned and belt ground surfaces.

Belt ground and honed textures have comparable Vmp and $S p k$ parameters and similar tribological properties. This is due to minimum Vmp and $S p k$ values in comparison to the turned surfaces.

Open Access This article is distributed under the terms of the Creative Commons Attribution License which permits any use, distribution, and reproduction in any medium, provided the original author(s) and the source are credited.

\section{References}

1. Jiang XJ, Whitehouse DJ (2012) Technological shifts in surface metrology. CIRP Ann Manuf Technol 61(2):815-836

2. De Chiffre L, Lonardo PM, Trumpold H, Lucca DA, Goch G, Brown CA, Raja J, Hansen HN (2000) Quantitative characterization of surface texture. CIRP Ann Manuf Technol 49(2):635-652

3. Lonardo PM, Trumpold H, De Chiffre L (1996) Progress in 3D surface microtopography characterization. CIRP Ann Manuf Technol 45(2):589-598

4. Tönshoff HK, Arendt C, Ben Amor C (2000) Cutting of hardened steel. CIRP Ann Manuf Technol 49(2):547-566

5. Klocke F (2011) Manufacturing processes 1. Cutting. Springer, Berlin

6. König W, Berktold A, Koch KF (1993) Turning versus grinding-a comparison of surface integrity aspects and attainable accuracies. CIRP Ann Manuf Technol 42(1):39-43

7. Davim JP (2011) Machining of hard materials. Springer, London

8. Klocke F, Brinksmeier E, Weinert K (2005) Capability profile of hard cutting and grinding processes. CIRP Ann Manuf Technol 54(2): $557-580$

9. Grzesik W, Rech J, Wanat T (2007) Surface finish on hardened bearing steel parts produced by superhard and abrasive tools. Int J Mach Tools Manuf 47:255-262

10. Grzesik W, Żak K (2012) Modification of surface finish produced by hard turning using superfinishing and burnishing operations. J Mater Process Technol 212:315-322

11. Griffiths B (2001) Manufacturing surface technology. Surface integrity and functional performance. Penton Press, London

12. Leach R (2013) Characterization of areal surface texture. Springer, Berlin

13. Michigan Metrology (2014) 3D surface roughness and wear measurements, analysis and inspection; Available at www. michmet.com 